\title{
Design and Manufacuring of Coal Excavating Robot
}

\author{
Saisugun Dontha ${ }^{1}$, Srikiran Vempati ${ }^{2}$, Syed Amer Ali Hussaini ${ }^{3}$, \\ T. Pavan Kumar ${ }^{4}$ \\ ${ }^{1,2,3}$ B. Tech, Dept. of Mechanical Engineering, Vidya Jyothi institute of technology, Hyderabad, Telangana, \\ INDIA \\ ${ }^{4}$ Assistant Professor, Dept. of Mechanical Engineering, Vidya Jyothi institute of technology, Hyderabad, \\ Telangana, INDIA
}

\begin{abstract}
Coal excavating robot is the remote controlled robot can be used in mines to excavate coal with utmost efficiency and minimum human intervention. In some coal mines labour work extremely hard to shovel and load the coal in trucks in harsh temperatures, heavy work load and stressful conditions. Labour risks their health and life to do hazardous work in shoveling coal from mines. Labour life risks in coal mines can be reduced by implementing coal excavating robot in coal mines to excavate coal. Coal excavating robot has a scoop shaped heavy loader bucket in front side of robot to load the coal in mines. Loader bucket, links and Robot body frame of robot are designed in Solid works 2016 designing software. Loader bucket teeth are designed with penetration type of bucket teeth to penetrate in to coal. Bucket teeth are designed in seven in number. Finite element analysis is done on Loader bucket in ansys15.0. Software to calculate stresses and total deformation. Material used in manufacturing of coal excavating robot is AISI 1018 low carbon Mild steel.
\end{abstract}

Keywords: actuator, loader bucket, links

\section{Introduction}

In general, large excavating jobs are done using big excavating machines and heavy equipment but in some small excavations labour work hard using shovels to shovel the coal under extremely dangerous situations. To overcome all these problems coal excavating robot can be used. Coal excavating robot parts loader bucket, robot body frame and links are designed in solid works 2016 designing software. All the parts of the robot are fabricated using different machining processes in workshop. The material used is mild steel of two different thickness sheets. 3D models of robot parts are designed with the referenced dimensions and some other parts are purchased. To calculate the forces and deformation on the loader bucket Finite element analysis is done in ansys15.0.

\subsection{Loader Bucket:}

\section{3D Modelling Of Robot Parts}

3D modelling of robot parts i.e. loader bucket, robot body frame and links are designed according to the referenced MMGS dimensions in solid works 2016 software. To design loader bucket, in front plane of part drawing side plate sketch is drawn and extruded using boss-extrude tool. Using mirror tool, side plate is mirrored to the other side of reference plane. A reverse offset sketch is drawn on side plate and extruded it up to surface of other side to form a solid body. To the base edge of the loader bucket teeth sketch is drawn and to bring it in to shape boss extrude and extruded cut tools are used. Using linear pattern tool bucket teeth are linear patterned seven in number. Sketch of side ware plates are drawn and extruded underneath the loader bucket base. Sketch of Hinge plate is drawn and extruded with an extruded cut hole. Using mirror tool hinge plate is mirrored to the other side of reference plane. To chamfer the sharp edges fillet tool is used. The solid body of loader bucket is ready ad shown in the Fig.1.

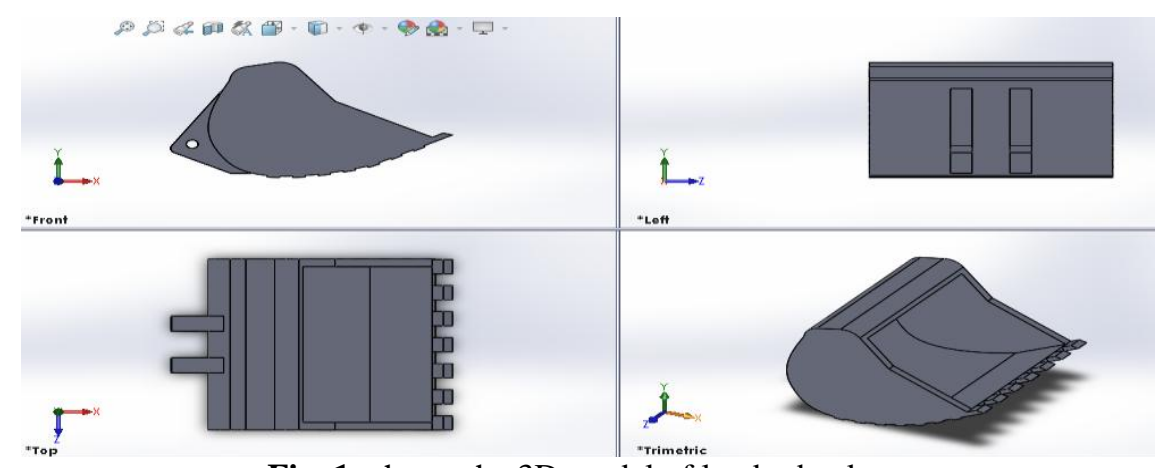

Fig. 1: shows the 3D model of loader bucket. 


\subsection{Robot Body Frame And Links:}

3D models of robot body frame and 2 links are designed using the similar tools as in design of loader bucket but with other dimensions and sketches as shown in the Fig. 2 and Fig.3.

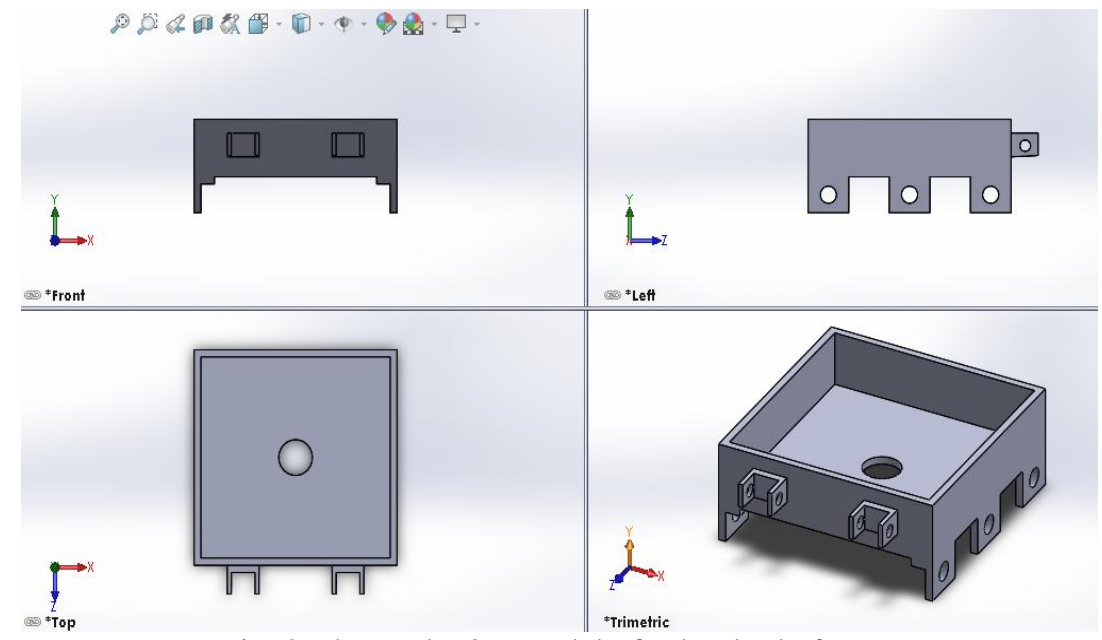

Fig. 2: shows the 3D model of robot body frame

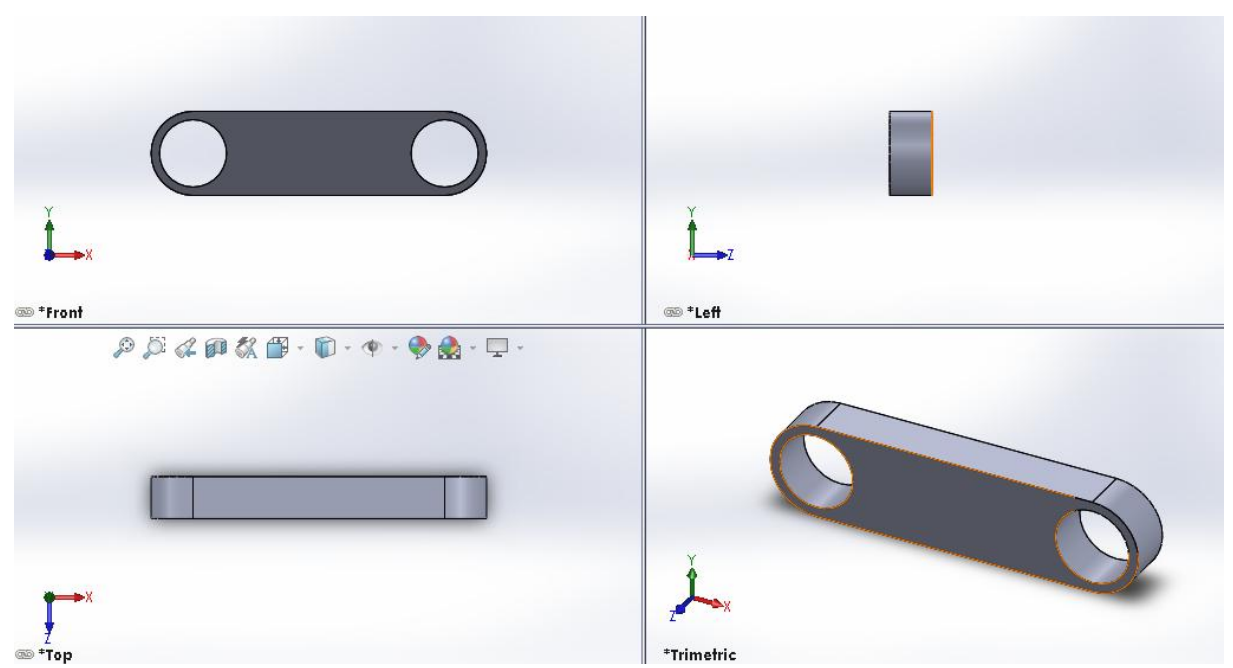

Fig. 3: shows the 3D model of links

\section{Finite Element Analysis Of Loader Bucket:}

Loader bucket is designed in solid works 2016 software and then Geometry is imported in to ansys15.0. as IGES file. In ansys workbench static structural is selected in analysis systems and it is dragged to standalone system. In engineering data mechanical properties of mild steel material are added as new material in add a new material option as shown in the Table 1 [2].

Table 1: material properties of AISI 1080 carbon steel

\begin{tabular}{|l|l|}
\hline Density & $7.87 \mathrm{~g} / \mathrm{cm}^{3}$ \\
\hline Young's modulus & $210 \mathrm{GPa}$ \\
\hline Poisson's ratio & 0.3 \\
\hline Tensile yield strength & $370 \mathrm{MPa}$ \\
\hline Tensile ultimate strength & $440 \mathrm{MPa}$ \\
\hline
\end{tabular}

In model tetrahedral mesh is generated with 11130 nodes and 5238 elements as shown in the Fig. 3. The hinge plate holes are selected as fixed supports and force is given on bucket teeth in anti-clock wise direction as shown in the Fig. 3. 

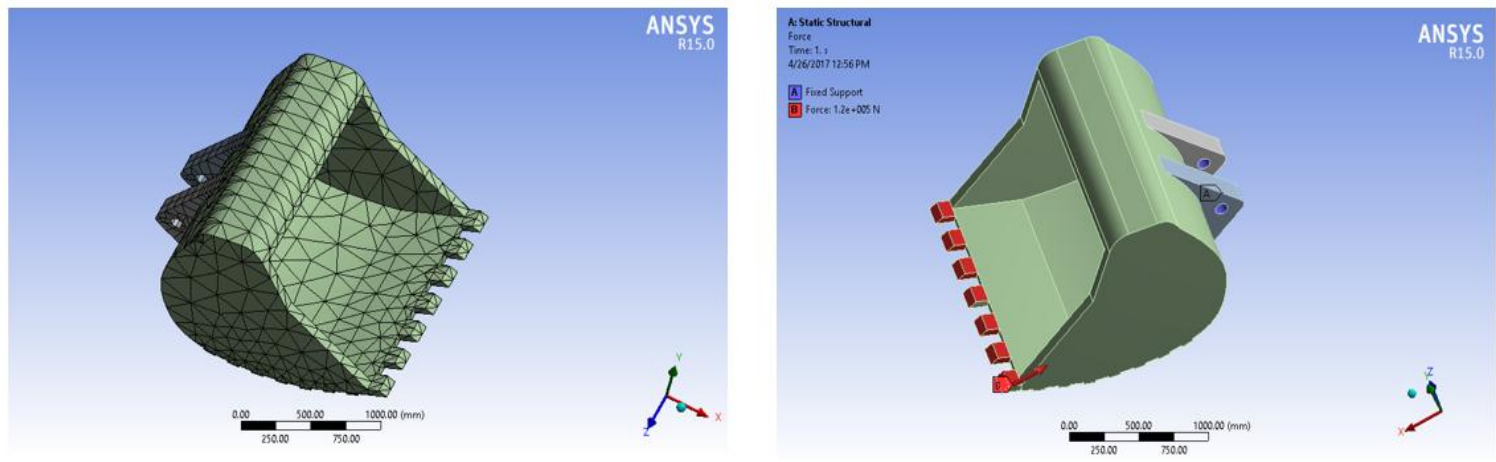

Fig. 3: shows the mesh, forces and fixed supports

To calculate the forces for solution Equivalent (Von-mises) stress and total deformation are selected. The force applied at $\mathrm{x}$-component is $1000000 \mathrm{~N}$. Fig. 4 shows the Equivalent (Von-mises) stress value as $188.72 \mathrm{MPa}$ and total deformation as $8.3622 \mathrm{~mm}$.
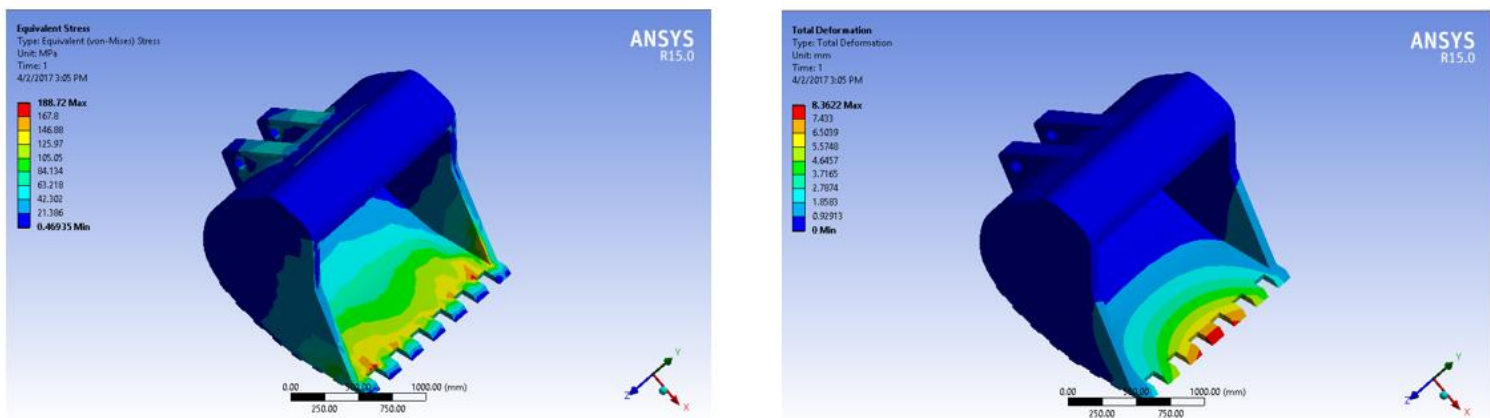

Fig. 4: shows the Equivalent (Von-mises) stress and total deformation values

\subsection{Analysis Results:}

From the above analysis it is found that the Design of loader bucket is safe because the Equivalent (Von-mises) stress value generated is $188.72 \mathrm{MPa}$ which is well below the ultimate tensile strength value(440MPa) of AISI low carbon mild steel and the total deformation value is $8.3622 \mathrm{~mm}$.

\subsection{Loader Bucket:}

\section{Manufacturing Of Coal Excavating Robot Parts:}

Loader bucket is a scoop shaped bucket fabricated with Mild Steel sheet of $2 \mathrm{~mm}$ thickness. This irregular sheet is cut in to dimensions of $30 \times 25 \times 0.2 \mathrm{~cm}$ using a hand cutting machine. Then this sheet is bent in to scoop shape using manual bending process. Then the side plates are exactly cut in to the scoop shape of the bucket are welded on either sides of the bent sheet to form the bucket shape. Hinge Plates are made of same Mild Steel material but with $3 \mathrm{~mm}$ thickness plate. These plates are cut in to shape with Gas cutting as shown in the Fig. 5. After cutting the Hinge Plates, edges of Plates are surface finish with Grinding Machine and Holes are drilled with $\emptyset 12 \mathrm{~mm}$ drill bit. Then these Hinge plates are welded to the back side of the bucket with arc welding at $5 \mathrm{~cm}$ distance from side plates and $10 \mathrm{~cm}$ distance in between them. Bucket Teeth are made of mild steel $1 \times 1 \mathrm{~cm}$ square bar. Teeth are cut in to seven number of pieces of $3 \mathrm{~cm}$ long from square bar as shown in the Fig. 5. The teeth are now welded to the base edge of the bucket with an equal distance of $5 \mathrm{~cm}$ on the base edge of bucket and surface finish the teeth. Now all the welded parts are surface finish with hand grinding machine. Now the manufacturing of Loader bucket is completed as shown in the Fig. 5.
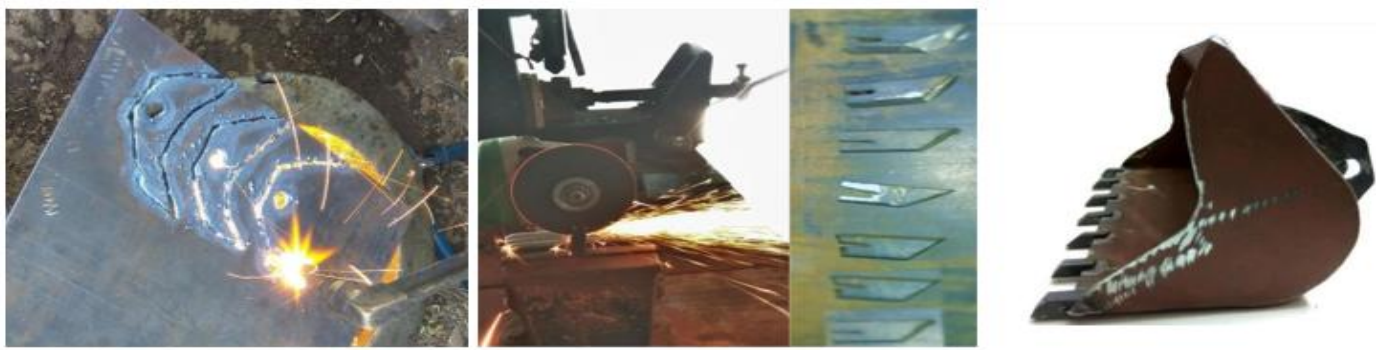

Fig. 5: shows the manufacturing of loader bucket. 


\subsection{Robot Body Frame:}

Robot Body Frame or Chassis is fabricated with $3 \mathrm{~mm}$ thickness irregular shaped mild steel plate which is cut in to area of $30 \mathrm{~cm}^{2}$ plate and four $30 \times 8 \mathrm{~cm}$ plates with oxy-acetylene cutting or Gas cutting and surface finish with hand grinding machine. Then they are arranged in square frame and welded with arc welding as shown in the Fig. 6. Then two $30 \times 1 \times 0.3 \mathrm{~cm}$ Mild Steel strips are cut with Oxy acetylene cutting and weld them to the either side of two opposite walls of the frame which is used for sliding the top surface cover plate. Then six Galvanized Iron L-shaped clamps are welded underneath the metal frame in such a position that the axes of clamps are symmetric as shown in the Fig. 6. Then two C- shaped Mounting brackets in front side of the Metal frame are welded to hold the links and the actuator to control the Loader bucket. A $\varnothing 12 \mathrm{~mm}$ hole is drilled at the center of the frame so, that wire can fasten through the frame to run the motors. Now the manufacturing of robot body frame is completed as shown in Fig. 6.
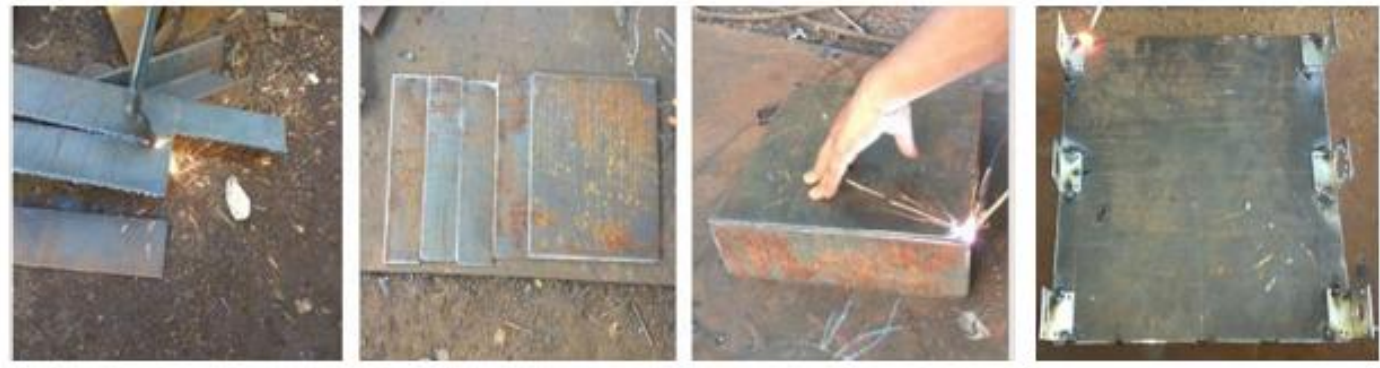

Fig. 6: shows the manufacturing of robot body frame.

\subsection{Linear Actuator:}

Linear actuator is an actuator that creates motion in a straight line, in contrast tothe circular motion of a conventional electric motor. Main parts of the linear actuator are Lead screw, coupler, nut and a metal square tube. A M10 acme threaded $100 \mathrm{~mm}$ long screw is taken and at its one end is turned to Ø6mm in lathe machine and drill a $\varnothing 3 \mathrm{~mm}$ hole in it so, that the coupler holds the motor shaft and lead screw end at same axis as shown in the Fig. 7. Now fix the nut inside the metal square tube and Insert the lead screw inside the square tube through the nut so, that the square tube creates the linear motion due to the circular motion of lead screw. Now the manufacturing ofthe linear actuator part is completed as shown in the Fig. 7.

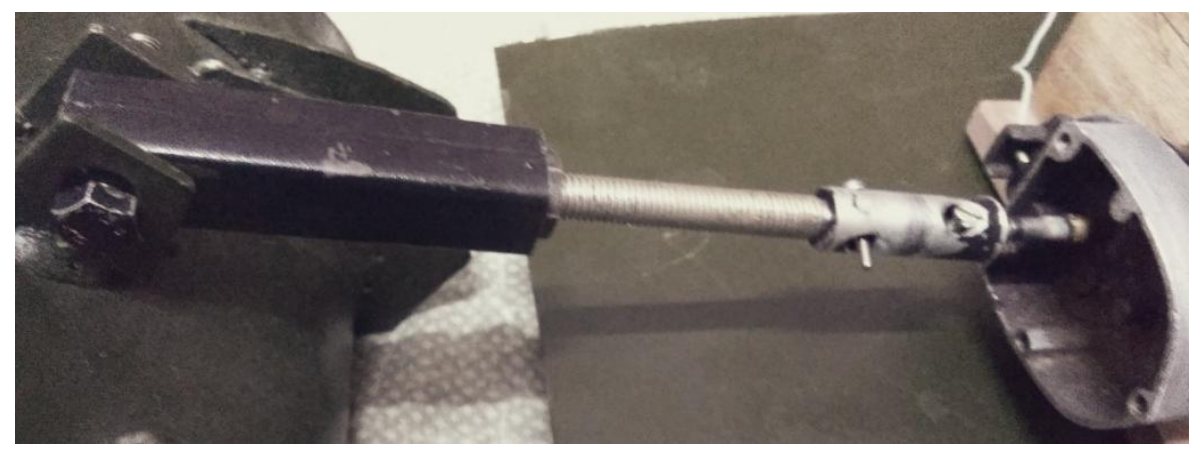

Fig. 7: shows the fabricated linear actuator

\subsection{Assembly Of Coal Excavating Robot Parts:}

Assembling the fabricated parts to form a Machine or a Robot is a difficult task. First the actuator parts are assembled to form a linear actuator and its one end is mounted to the front end of Robot body frame and other end to the Loader Bucket. All the Fabricated parts are painted. The designed links are mounted between robot frame and bucket hinge plates using a $3 \mathrm{~cm}$ long M8 bolts and nuts. All the six motors are mounted to the six L clamps so that the axes should be symmetric. six wheels are mounted to the motor shafts. Then all the motors and linear actuator connections are connected in series connection using wires and those wires are connected to the power source and from power source to the remote controller. The position of the loader bucket is adjusted by trial and error method. All the electronic connections in positions according to the color codes and also the position of the power source is adjusted. Now the coal excavating Robot is assembled as shown in the Fig. 8. 


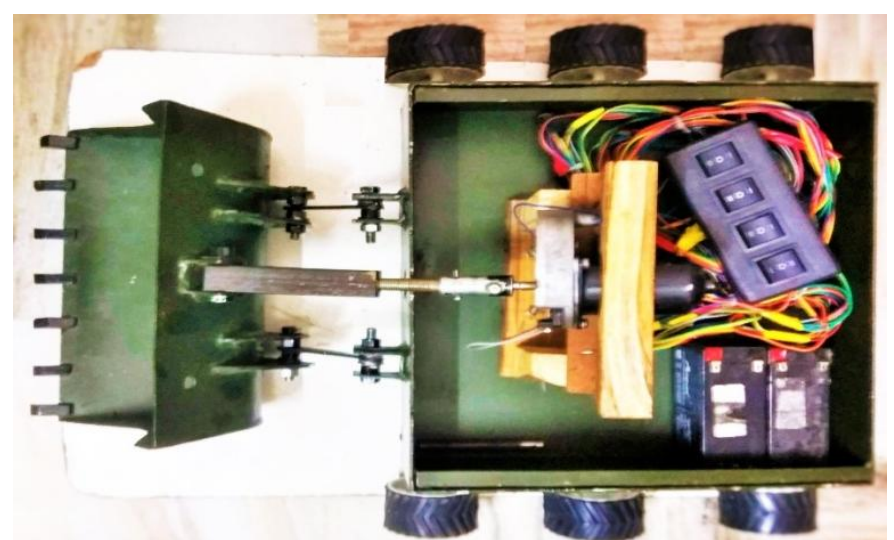

Fig. 8. shows the assembled coal excavating robot

\section{Conclusion}

The coal excavating robot parts are designed in solid works 2016 designing software. Finite element analysis is done on loader bucket part in ansys15.0. From the analysis it is found that the Design of loader bucket is safe because the Equivalent (Von-mises) stress value generated is $188.72 \mathrm{MPa}$ which is well below the ultimate tensile strength value(440MPa) of AISI 1018 low carbon mild steel and the total deformation value is $8.3622 \mathrm{~mm}$.

In Future, to reduce the human life risks due to harsh stress and hazardous conditions in coal mines, Coal Excavating robot can be used to reduce the life risks of labour in mines by performing coal excavating and shoveling operations in mines with utmost efficiency and minimum human intervention.

\section{References}

[1]. Yashpalchopra, ParveshDahiya, SushilKashyup, "Design and analysis of a multipurpose loader bucket” IJARESM, vol 4, issue: 8, August - 2016, ISSN: 2455-6211

[2]. http://www.azom.com/article.aspx?ArticleID=6115

[3]. http://www.caterpillar.com/ 